\title{
Could Management of Blood Pressure Prevent Dementia in the elderly?
}

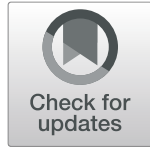

\author{
Masaki Mogi(i)
}

\begin{abstract}
Background: Hypertension is one of the most relevant risk factors in vascular aging, stroke and vascular dementia (VD). In the elderly, the prevalence of mixed dementia, which consists of Alzheimer's disease (AD) and VD, is increased. Moreover, disorders of blood vessels are reported to be involved in the onset and progression of AD. Thus, hypertension generally plays an important role in dementia overall.

Main Text: Mid-life hypertension is reported to be related to the incidence of dementia, but it is reported that antihypertensive treatment in aged people cannot prevent the onset and progression of dementia. The reninangiotensin system (RAS) is deeply involved in not only hypertension but also lifestyle-related diseases, and may contribute to the pathological mechanism in dementia; thus, RAS regulation is expected to prevent dementia. Small vessel structural changes in lifestyle-related diseases may play a role in dementia in the elderly.

Conclusion: Here, we discuss the role of blood pressure elevation in dementia and the therapeutic possibility of antihypertensive treatment against dementia.
\end{abstract}

Keywords: Hypertension, Mixed dementia, Renin-angiotensin system, Blood brain barrier, Vascular degeneration

\section{Background}

Life expectancy is increasing worldwide. Especially, Asian countries such as Japan and South Korea face the serious problem of a longer lifespan. In South Korea, prolongation of life will be the largest worldwide, with life expectancy set to hit 90 years by 2030 [1]. We are now venturing into an unknown world in which life expectancy is over 90 years.

A more serious problem is the increase in people with dementia. The World Health Organization reports that dementia cases have tripled worldwide [2]. Especially in Asia, people with dementia will reach 70 million by 2050. In South Korea, the number of demented people is expected to double in ten years. On the other hand, the number of demented people will reach 7 million by 2025 in Japan. Unarguably, the demented population will become a severe worldwide problem in the near future.

However, new Alzheimer's disease drugs have not emerged over the last decade. A review [3] reported that in 2010, four drugs, acetylcholine esterase inhibitors such as donepezil, rivastigmine, galantamine, and a N-methyl$\mathrm{d}$-aspartate (NMDA) receptor antagonist, memantine,

Correspondence: mmogi@m.ehime-u.ac.jp

Department of Pharmacology, Ehime University, Graduate School of Medicine, Matsuyama, Japan

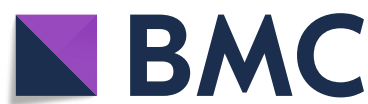

were currently used drugs, but others had been developed. Although many clinical and experimental studies have been performed, however, the situation is unchanged in 2019. Moreover, treatment for Alzheimer's disease using these four kinds of drugs is not radical. So, what should we do to overcome this serious problem? Potential brain mechanisms to be utilized in preventive strategies against dementia are reported in the Lancet [4]. According to the report, multi-domain lifestyle intervention such as increasing brain cognitive reserve, reducing brain damage, and reducing brain inflammation is necessary to prevent dementia. Vascular protection is involved in the reduction of brain damage. The American Heart Association also recommends increasing seven cardiovascular health metrics that people can improve through lifestyle changes, including maintaining untreated blood pressure below $120 / 80 \mathrm{mmHg}$ [5]. A three-city study indicated that higher levels of such metrics were associated with lower incidence of dementia in 6626 elderly more than 65 years old [6], indicating that vascular protection via appropriate blood pressure management is a recommended lifestyle modification to prevent dementia.

Epidemiological studies indicate potentially modifiable risk factors for dementia [4]. Among them, lifestyle related diseases such as hypertension, diabetes, and obesity

(c) The Author(s). 2019 Open Access This article is distributed under the terms of the Creative Commons Attribution 4.0 International License (http://creativecommons.org/licenses/by/4.0/), which permits unrestricted use, distribution, and reproduction in any medium, provided you give appropriate credit to the original author(s) and the source, provide a link to the Creative Commons license, and indicate if changes were made. The Creative Commons Public Domain Dedication waiver (http://creativecommons.org/publicdomain/zero/1.0/) applies to the data made available in this article, unless otherwise stated. 
contribute to dementia, especially in middle age. They induce vascular dysfunction, which causes loss of energy consumption by the neuron and results in neuronal dysfunction. Thus, the management of lifestyle-related diseases, such as hypertension, may prevent the onset or progression of dementia through vascular protection.

\section{Main text}

\section{Influence of mid-life hypertension on dementia}

Mid-life hypertension is reported to be a factor inducing dementia. Mid-life is typically defined as $45-64$ years old. In this manuscript, mid-life hypertension means hypertension in individuals approximately 50 years old, and late-life hypertension means hypertension in those approximately more than 70 years old. On the other hand, early-life hypertension is meaningless because individuals with hypertension before mid-life could have a risk for the development of dementia. The Atherosclerosis Risk in Communities (ARIC) cohort showed that high blood pressure in mid-life (around 48-67 years old) induces poorer cognitive function or dementia 20 years later [7]. Moreover, the Honolulu Heart Program or Honolulu Asia Aging Study demonstrated that subjects less than 50 year old, even those with prehypertension, had an increased risk for dementia only in the untreated group [8]. Interestingly, subjects receiving antihypertensive medication showed no increased risk for dementia, even in those with systolic blood pressure of more than $140 \mathrm{mmHg}$, indicating that early intervention in hypertension is one approach to prevent late-life dementia. So, what is the target level of blood pressure in mid-life to prevent dementia? Abell et al. reported that systolic blood pressure elevation at age 50 years is associated with increased risk of dementia [9]. Moreover, a systolic blood pressure level of $130 \mathrm{mmHg}$ or lower has been shown to significantly prevent dementia at age 50 . However, blood pressure elevation at 60 or 70 years old is not a significant risk, even in those with severe high blood pressure [9].

\section{Estimated mechanisms of mid-life hypertension-induced dementia}

Mid-life hypertension has been shown to be a risk for vascular dysfunction. Brain aging is considered to be induced not via neural aging, but via dysfunction of a coordinated and interactional system of neurons, astrocytes, and microvessels in the brain called the "neurovascular unit". A chronic hypertensive state induces cerebrovascular degeneration such as vascular remodeling, vascular hypertrophy, atherosclerosis, endothelial dysfunction and increased blood brain barrier permeability, resulting in disorder of the neurovascular unit [10]. These results indicate that vascular degenerative disease causes neurodegenerative disease such as dementia including Alzheimer's disease. Therefore, recently Qiu et al. introduced the concept of dementia in the elderly as a condition of total life course events via vascular injury in mid-life, and cardio- or cerebrovascular disease in later life [11].

\section{Influence of late-life hypertension on dementia}

On the other hand, intervention for high blood pressure in the very elderly did not significantly reduce the incidence of dementia in the Hypertension In the Very Elderly Trial-COGnitive function assessment (HYVETCOG) trial [12]. Moreover, the HYVET cohort study demonstrated that orthostatic hypotension indicates an increased risk of dementia and cognitive decline [13]. Thus, intensive BP treatment to prevent dementia is not recommended in "very elderly people" because blood pressure lowering fails to maintain cerebral blood flow because of dysfunction of cerebral autoregulation. Therefore, the younger the age at which blood pressure is managed at an appropriate level the better in order to prevent cognitive decline.

\section{Renin-angiotensin-aldosterone system and dementia}

In the cardiovascular burden over the course of a lifetime, the renin-angiotensin system (RAS) plays an important role as a risk or inducing factor for cardio- and cerebrovascular disease. We have been investigating the effect of RAS on cognitive function using animal models. The effect of angiotensin (Ang) II, a main component of RAS, on cognition is controversial. Gard et al. previously reviewed the dual action of Ang II in memory and learning [14]. For example, Georgiev et al. demonstrated that Ang II facilitates learning and memory [15]. On the other hand, Kulakowska et al. and Barnes et al. showed that blockade of RAS with an Ang II type 1 receptor blocker (ARB) or Ang converting enzyme inhibitor (ACEi) facilitated memory and learning [16-18]. Thus, we investigated the effect of Ang II on learning ability using Tsukuba-hypertensive mice which are double transgenic for human renin and human angiotensinogen [19]. Wild-type (WT) and Tsukuba-hypertensive mice underwent shuttle avoidance test every week from 10 to 20 weeks old. WT mice showed an increase in avoidance rate (which means better cognition) during aging. Ang II-overexpressing mice exhibited improvement of learning ability at a younger age; however, during later age learning ability did not improve but was impaired, indicating that Ang II may facilitate learning temporarily, but continuous stimulation with Ang II may exhaust the neural system or induce damage in the brain, resulting in cognitive decline [20]. We previously reported the effect of diabetes mellitus on cognition using obese diabetic mice, KKAy [21]. Interestingly, RAS blockade by $\mathrm{ARB}$ inhibits diabetes-induced cognitive impairment in 
these mice via prevention of $\mathrm{BBB}$ disruption with attenuation of swollen astrocyte end-feet. Ito et al. demonstrated that swollen astrocyte end-feet compress micro-vessels and induce dysfunction of the microcirculation [22]. Ang II-overexpressing mice also showed BBB disruption even in younger mice (unpublished data). Recently, Franco et al. clearly showed the potential mechanisms of hypertension-induced cognitive deficit involving angiotensin II, which increases the superoxideproducing enzyme, NADPH oxidase 2 (NOX2), in perivascular macrophages and induces reactive oxygen species [23]. These basic experiments suggest a protective effect of RAS blockade on cognitive decline.

\section{Influence of BP control on dementia}

$\mathrm{Li}$ et al. demonstrated that subjects treated with an ARB exhibit a lower incidence of dementia and an increase in survival probability compared with subjects with other cardiovascular comparators, using the US Veteran Affairs database of 819,491 male subjects [24]. However, to date, BP lowering has not been shown conclusively to preserve cognitive function in a clinical trial [25]. Moreover, intervention for high blood pressure in the very elderly does not significantly reduce the incidence of dementia as described above [12], and orthostatic hypotension is an increased risk for dementia and cognitive decline [13], indicating several problems in the sample age (average age around 70 years) and observation period (less than 5 years). A short observation time and small number of subjects over middle age might affect the results of clinical trials. Further investigation is necessary to confirm the preventive effect of blood pressure lowering on cognition. The American Heart Association has published a scientific statement on hypertension on cognitive function [26]. This states "there is strong evidence of a deleterious influence of mid-life hypertension on late-life cognitive function, but the cognitive impact of late-life hypertension is less clear." It also states that "evidence from clinical trials that antihypertensive treatment improves cognition is not conclusive." Recently, the Systolic Blood Pressure Intervention Trial (SPRINT) Memory and Cognition in Decreased Hypertension (SPRINT MIND) demonstrated that intensive blood pressure lowering prevents mild cognitive impairment and possibly dementia and slows development of white matter lesions in the brain [27]. Average blood pressure was $121.4 \mathrm{mmHg}$ in the intensive-treatment group and $136.2 \mathrm{mmHg}$ in the standard treatment group. Thus, in the future more clinical trials are needed to provide evidence that "the lower the blood pressure, the lower the incidence of dementia".

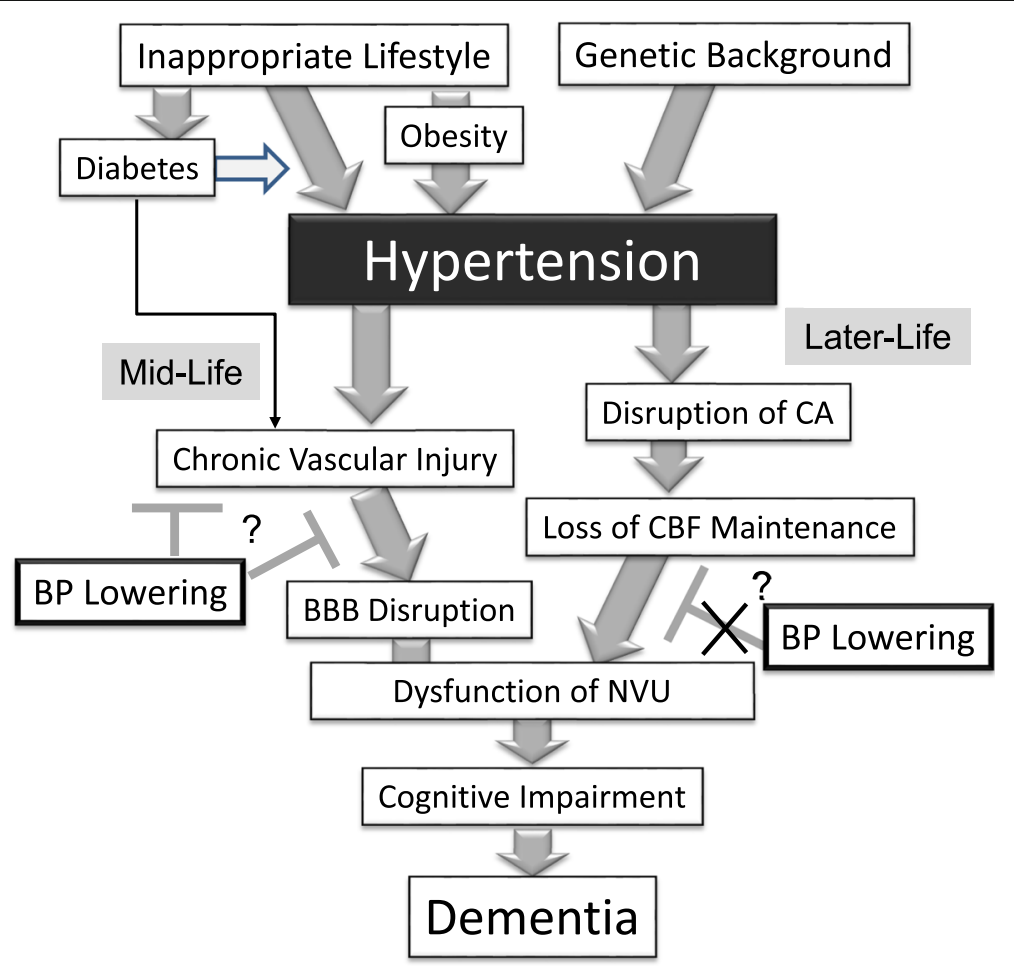

Fig. 1 Relation between hypertension and dementia. BBB; blood brain barrier, BP; blood pressure, CA; cerebral autoregulation, CBF; cerebral blood flow, NVU; 18 neurovascular unit 


\section{Recommendations for management of blood pressure to prevent dementia}

A summary of this review is presented in Fig. 1. Current recommendations for the management of blood pressure to prevent dementia are as follows:

1. Attention to untreated subjects with $\mathrm{BP}$ of more than $120 / 80 \mathrm{mmHg}$ for vascular health.

2. Subjects with systolic BP of more than $130 \mathrm{mmHg}$ without medication (mid-life hypertension) have increased future risk of dementia.

3. More attention is needed in subjects with other lifestyle risks.

4. There is no evidence that antihypertensive treatment can reduce the incidence of dementia, to date.

5. BP in "aged people" should be carefully managed, and BP lowering has no conclusive preventive effect on dementia in the very elderly.

6. However, the best way to prevent dementia in hypertensive patients is intensive treatment from middle age.

\section{Conclusions}

Management of hypertension from middle age may reduce the onset of dementia in the elderly. However, large clinical trials are necessary to confirm whether antihypertensive drugs prevent dementia.

\section{Abbreviations}

AD: Alzheimer's disease; Ang II: Angiotensin II; ARB: Angiotensin II type 1 receptor blocker; BBB: Blood brain barrier; RAS: Renin-angiotensin system; VD: Vascular dementia

\section{Acknowledgements}

Not applicable.

\section{Declarations}

This review is based on a presentation at Hypertension Seoul 2018.

\section{Authors' contributions}

MM wrote the manuscript. The author read and approved the final manuscript.

\section{Funding}

Not applicable.

\section{Availability of data and materials}

Not applicable.

\section{Ethics approval and consent to participate}

Not applicable.

\section{Consent for publication}

Not applicable.

\section{Competing interests}

The author declares that he has no competing interests.
Received: 27 August 2019 Accepted: 25 November 2019

Published online: 10 December 2019

\section{References}

1. Kontis V, Bennett JE, Mathers CD, Li G, Foreman K, Ezzati M. Future life expectancy in 35 industrialised countries: projections with a bayesian model ensemble. Lancet. 2017:389:1323-35.

2. International WHOaAsD. Dementia: a public health priority. 2012.

3. Mangialasche F, Solomon A, Winblad B, Mecocci P, Kivipelto M. Alzheimer's disease: clinical trials and drug development. Lancet Neurol. 2010;9:702-16.

4. Livingston G, Sommerlad A, Orgeta V, Costafreda SG, Huntley J, Ames D, et al. Dementia prevention, intervention, and care. Lancet. 2017;390: 2673-734.

5. My life check / life's simple 7. https://www.heart.org/en/healthy-living/ healthy-lifestyle/my-life-check\%2D\%2Dlifes-simple-7. Last Reviewed: 2 May 2018.

6. Samieri C, Perier MC, Gaye B, Proust-Lima C, Helmer C, Dartigues JF, et al. Association of cardiovascular health level in older age with cognitive decline and incident dementia. JAMA. 2018;320:657-64.

7. Gottesman RF, Schneider AL, Albert M, Alonso A, Bandeen-Roche K, Coker L, et al. Midlife hypertension and 20-year cognitive change: the atherosclerosis risk in communities neurocognitive study. JAMA Neurol. 2014;71:1218-27.

8. Launer LJ, Hughes T, Yu B, Masaki K, Petrovitch H, Ross GW, et al. Lowering midlife levels of systolic blood pressure as a public health strategy to reduce late-life dementia: perspective from the Honolulu heart program/ Honolulu Asia aging study. Hypertension. 2010:55:1352-9.

9. Abell JG, Kivimaki M, Dugravot A, Tabak AG, Fayosse A, Shipley M, et al. Singh-Manoux a. association between systolic blood pressure and dementia in the Whitehall II cohort study: role of age, duration, and threshold used to define hypertension. Eur Heart J. 2018;39:3119-25.

10. Faraco G, ladecola C. Hypertension: a harbinger of stroke and dementia. Hypertension. 2013;62:810-7.

11. Qiu C, Fratiglioni L. A major role for cardiovascular burden in age-related cognitive decline. Nat Rev Cardiol. 2015;12:267-77.

12. Peters R, Beckett N, Forette F, Tuomilehto J, Clarke R, Ritchie C, et al. Incident dementia and blood pressure lowering in the hypertension in the very elderly trial cognitive function assessment (HYVET-COG): a doubleblind, placebo controlled trial. Lancet Neurol. 2008;7:683-9.

13. Peters R, Anstey KJ, Booth A, Beckett N, Warwick J, Antikainen R, et al. Orthostatic hypotension and symptomatic subclinical orthostatic hypotension increase risk of cognitive impairment: an integrated evidence review and analysis of a large older adult hypertensive cohort. Eur Heart J. 2018:39:3135-43.

14. Gard PR. The role of angiotensin II in cognition and behaviour. Eur J Pharmacol. 2002:438:1-14.

15. Georgiev V, Yonkov D. Participation of angiotensin II in learning and memory. I. Interaction of angiotensin II with saralasin. Methods Find Exp Clin Pharmacol. 1985;7:415-8.

16. Costall B, Coughlan J, Horovitz ZP, Kelly ME, Naylor RJ, Tomkins DM. The effects of ACE inhibitors captopril and SQ29,852 in rodent tests of cognition. Pharmacol Biochem Behav. 1989;33:573-9.

17. Earley B, Burke M, Leonard BE. Effects of captopril on locomotor activity, passive avoidance behaviour and spatial memory tasks in the trimethyltintreated rat. Neuropsychobiology. 1989;22:49-56.

18. Kulakowska A, Karwowska W, Wisniewski K, Braszko JJ. Losartan influences behavioural effects of angiotensin II in rats. Pharmacol Res. 1996;34:109-15.

19. Fukamizu A, Sugimura K, Takimoto E, Sugiyama F, Seo MS, Takahashi S, et al. Chimeric renin-angiotensin system demonstrates sustained increase in blood pressure of transgenic mice carrying both human renin and human angiotensinogen genes. J Biol Chem. 1993;268:11617-21.

20. Inaba S, Iwai M, Furuno M, Tomono Y, Kanno H, Senba I, Okayama H, Mogi M, Higaki J, Horiuchi $M$, et al. Continuous activation of renin-angiotensin system impairs cognitive function in renin/angiotensinogen transgenic mice. Hypertension. 2009:53:356-62.

21. Min LJ, Mogi M, Shudou M, Jing F, Tsukuda K, Ohshima K, et al. Peroxisome proliferator-activated receptor-gamma activation with angiotensin II type 1 receptor blockade is pivotal for the prevention of blood-brain barrier impairment and cognitive decline in type 2 diabetic mice. Hypertension. 2012;59:1079-88. 
22. Ito U, Hakamata Y, Kawakami E, Oyanagi K. Temporary cerebral ischemia results in swollen astrocytic end-feet that compress microvessels and lead to delayed focal cortical infarction. J Cereb Blood Flow Metab. 2011;31:328-38.

23. Faraco G, Sugiyama Y, Lane D, Garcia-Bonilla L, Chang H, Santisteban MM, et al. Perivascular macrophages mediate the neurovascular and cognitive dysfunction associated with hypertension. J Clin Invest. 2016;126:4674-89.

24. Li NC, Lee A, Whitmer RA, Kivipelto M, Lawler E, Kazis LE, et al. Use of angiotensin receptor blockers and risk of dementia in a predominantly male population: prospective cohort analysis. BMJ. 2010;340:b5465.

25. Gorelick PB, Furie KL, ladecola C, Smith EE, Waddy SP, Lloyd-Jones DM, et al. Defining optimal brain health in adults: a presidential advisory from the American Heart Association/American Stroke Association. Stroke. 2017;48: e284-303.

26. Iadecola C, Yaffe K, Biller J, Bratzke LC, Faraci FM, Gorelick PB, et al. Impact of hypertension on cognitive function: a scientific statement from the American Heart Association. Hypertension. 2016;68:e67-94.

27. Kjeldsen SE, Narkiewicz K, Burnier M, Oparil S. Intensive blood pressure lowering prevents mild cognitive impairment and possible dementia and slows development of white matter lesions in brain: the SPRINT memory and cognition IN decreased hypertension (SPRINT MIND) study. Blood Press. 2018;27:247-8

\section{Publisher's Note}

Springer Nature remains neutral with regard to jurisdictional claims in published maps and institutional affiliations.

Ready to submit your research? Choose BMC and benefit from:

- fast, convenient online submission

- thorough peer review by experienced researchers in your field

- rapid publication on acceptance

- support for research data, including large and complex data types

- gold Open Access which fosters wider collaboration and increased citations

- maximum visibility for your research: over $100 \mathrm{M}$ website views per year

At BMC, research is always in progress.

Learn more biomedcentral.com/submissions 